\title{
Refractometria na determinação do teor de açúcar e de aspartame em bebidas comerciais
}

\section{Introdução}

\section{Os Açúcares: onde e como existem}

Uma grande quantidade dos alimentos que consumimos diariamente contêm açúcar. Este é o nome utilizado genericamente para referir uma série de compostos orgânicos - hidratos de carbono -, de fórmula geral $\mathrm{C}_{n}\left(\mathrm{H}_{2} \mathrm{O}\right)_{n}$, em que $n$ é um número entre 3 e 6 , bem como dímeros ou oligómeros destes compostos, figura 1. Os hidratos de carbono são produzidos nas plantas, durante o processo fotossintético. Podemos encontrá-los, por exemplo, nos cereais, na cana de açúcar, na beterraba açucareira, nos frutos, no leite e no mel, entre outros, alimentos estes que são conhecidos como fontes de energia fundamentais para os animais e para o homem.

\section{Na Dieta Humana: benefícios e malefícios}

Os polímeros de hidratos de carbono, como o amido ou a celulose, são mais recomendáveis para a dieta humana do que os hidratos de carbono simples. 0 amido, presente no arroz, batatas, pão e cereais, é uma excelente fonte de energia, enquanto que a celulose é um importante fornecedor de fibra na alimentação. No que respeita a uma dieta diária equilibrada, recomenda-se, em geral, que aproximadamente $58 \%$ das calorias devam ser obtidas a partir de hidratos de carbono, e não mais do que $10 \%$ devam ser originadas pela glucose.

No entanto, apesar do bem que sabe, a ingestão de açúcar em excesso conduz às conhecidas cáries dentárias, provo- cadas pela degradação da Sacarose (dímero de glucose e frutose), devida a uma bactéria denominada Streptococcus mutans, presente na saliva humana, e a outros problemas como a obesidade. Desta forma, uma diminuição da quantidade de açúcar ingerido é benéfica para a manutenção de uma boa saúde, razão pela qual os açúcares contidos em alimentos e bebidas têm sido progressivamente substituídos por adoçantes naturais ou de origem sintética que, preservando o sabor doce, não contêm glucose.

\section{A alternativa ... doce}

Um destes adoçantes é o Aspartame (figura 1), descoberto em 1965, e que em 1981 se converteu no primeiro adoçante de baixo teor calórico, aprovado pela Food and Drug Administration nos Estados Unidos, para a utilização em diversos alimentos e bebidas, nomeadamente refrigerantes. 0 aspartame é sintetizado a partir de dois aminoácidos, a L-fenilalanina e o ácido L-aspártico, sendo aproximadamente 200 vezes mais doce do que a sacarose. Este facto permite, para obter a mesma doçura, a redução das calorias ingeridas em cerca de $99,4 \%$, ou seja, menos de $1 \%$ da quantidade de sacarose necessária! A utilização deste adoçante apresenta uma série de vantagens para a saúde: ajuda no controlo das calorias ingeridas, não provoca a degradação dos dentes, intensifica os sabores (evitando a adição de outros produtos com a mesma finalidade, às comidas e bebidas industriais) e é aceitável em dietas próprias para diabéticos.
Os sumos e refrigerantes que se podem encontrar actualmente à disposição do consumidor, dividem-se em dois grandes grupos: os açucarados e os designados como light. Neste último grupo, os açúcares, essencialmente glucose e frutose[1], são substituídos por adoçantes, sendo o mais utilizado, o referido aspartame. As normas de consumo obrigam os fabricantes a indicar o teor de açúcar ou aspartame contidos nas bebidas (apesar dessa informação nem sempre ser perceptível nos rótulos dos produtos vendidos em Portugal), pelo que a análise do teor de açúcares/adoçantes tem um papel muito importante no controlo de qualidade dos alimentos.

\section{Análise dos Teores de Açúcar (Sacarose) em Bebidas}

Diversas são as técnicas disponiveis para análise de soluções aquosas contendo solutos diversos. Destas, destacam-se a cromatografia [2] [3], a densitometria[4], a espectroscopia de infravermelho de reflectância [5] [6] [7], a polarimetria[2] e a refractometria de laser[8].

Tanto a densitometria como a refractometria têm sido populares no controlo de qualidade de amostras líquidas, porque as determinações da densidade ou do índice de refracção são, na maioria dos casos, as formas mais simples e mais rápidas, de caracterizar um líquido ou determinar a concentração de um determinado componente nele incluído. Exemplos clássicos de medidas de concentração utilizando estas técnicas, são a determinação do teor de sacacrose em soluções de açúcar (BRIX) por re-

\footnotetext{
• Departamento de Química da Universidade de Coimbra, Rua Larga, 3049-535 Coimbra, Portugal
} 
<smiles>OC[C@H]1O[C@H](O)[C@@H](O)[C@H](O)[C@H]1O</smiles>

Ribose

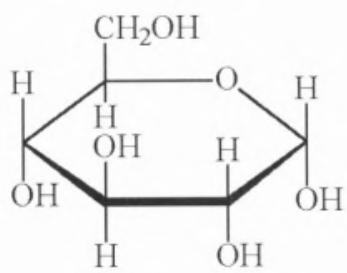

$\alpha$-glicose

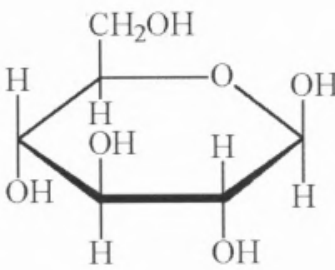

$\beta$-glicose

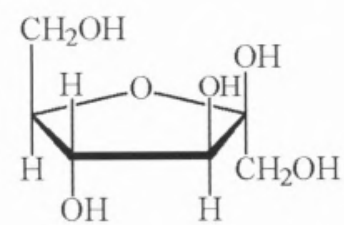

Frutose<smiles>COC(=O)C(Cc1ccccc1)NC(=O)C(N)CC(=O)O</smiles>

figura 1 Estruturas de alguns açúcares e do aspartame

fractometria ou a determinação de álcool utilizando hidrómetros.

\section{Refracção - Alguns Fundamentos Básicos}

A refracção é o fenómeno segundo o qual, quando um raio luminoso passa obliquamente de um meio para outro, de densidade diferente, toma uma direcção diferente. 0 raio luminoso no primeiro meio designa-se por raio incidente, e no segundo, designa-se por raio refractado. 0 ângulo formado pelo raio incidente e a superfície de separação (ou normal), chama-se ângulo de incidência, i; o ângulo correspondente no segundo meio chama-se ângulo de re- fracção, r. O seno de ie o seno de $r$ são directamente proporcionais às velocidades da luz nos dois meios, e a relação seni/senr toma o nome de índice de refracção, $n$ (ver figura 2). Visto de outra forma, o índice de refracção de um meio é definido por $n=c N$, sendo $v$ a velocidade de propagação da luz nesse meio e c a velocidade de propagação da luz no vazio.

0 índice de refracção para um dado sistema de dois meios, varia com a temperatura e com o comprimento de onda da luz. A figura 2 pretende ilustrar, de uma forma esquemática, o fenómeno da refracção da luz passando de um meio 1 para um meio 2. Mantendo constantes estes factores, torna-se numa constante característica do meio a que diz respeito. Por isso, é utilizável na identificação de compostos e na determinação de concentrações, em misturas binárias homogéneas, de compostos conhecidos. O seu valor teórico é, como advém da anterior relação, referenciado relativamente ao vazio (apesar de o mais utilizado ser o índice referido ao ar, que difere daquele apenas em 0,03\%), ao comprimento de onda da risca $D$ do Sódio $(589 \mathrm{~nm})$ e à temperatura de $20^{\circ} \mathrm{C}$, designando-se, nestas condições, por $n_{D}^{20}$.

figura 2 Desenho esquemático da variação da direcção da luz quando passa de um meio 1 para um meio 2 .

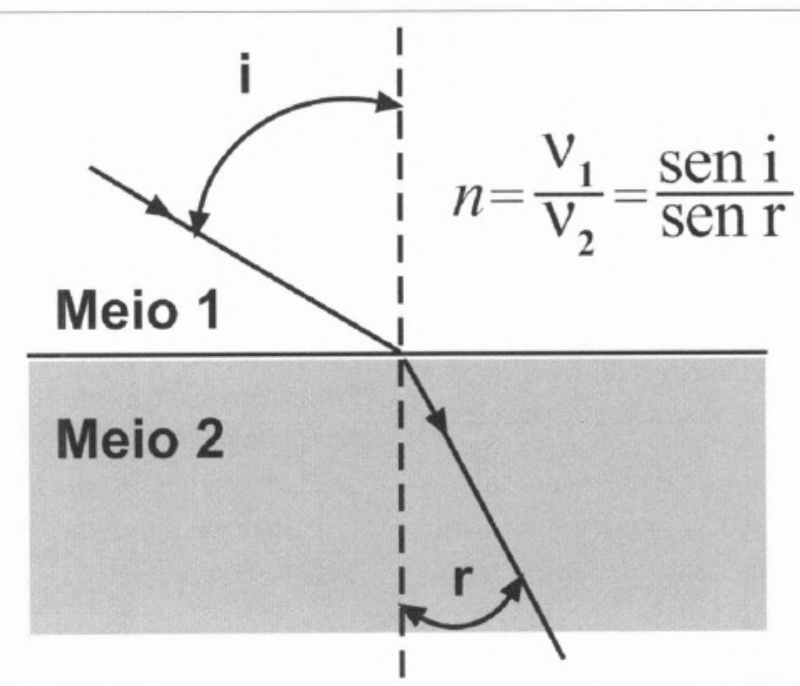


A refractometria é, pois, o método experimental de determinação de uma constante física característica de um meio: o

\section{Um Pouco de História : o \\ Refractómetro de Abbe}

$\mathrm{Na}$ análise de soluções (determinação de concentrações e composição de misturas, controle do grau de pureza, etc.), pelo método refractométrico, o aparelho de medida mais comum é o refractómepetroquímica, farmacêutica, química, etc. É também normalmente este refráctometro que se encontra nos diversos laboratórios de ensino. Tomou o nome do seu criador, Ernst Abbe, um físico alemão nascido em 1840, especializado em óptica, que foi o primeiro a formular uma teoria completa sobre a formação das imagens nos microscópios. Em 1873 , baseando-se nas suas investigações e em colaboração com Zeiss, construiu um novo tipo de microscópio, mais potente e de maior qualidade do que os então existentes. Ao inventar o refractómetro, associou-lhe igualmente o número de Abbe: 0 inverso do poder dispersivo ou da dispersão de um material. Curiosamente, e em parte sinal da gete na ideia de Abbe, o primeiro instrumento contém todas as características essenciais de um refractómetro de Abbe moderno (figura 3), excepção feita à inexistência de um termóstato para controlo da temperatura.

\section{A Experiência: Determinação de Teores de Açúcar e de Aspartame em Bebidas}

Um refractómetro de Abbe faz parte do equipamento da maioria dos laboratórios de Química. Pretende-se, com este trabalho, mostrar como pode ser simindice de refracção. tro de Abbe, sendo utilizado na indústria nialidade e perfeccionismo então paten-

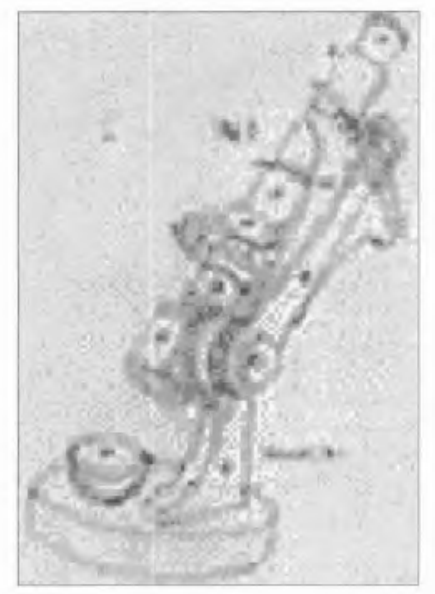

figura 3 Reprodução do desenho original do refractómetro de Abbe[9][10].

ples a determinação do teor de açúcar e de adoçante (aspartame) em sumos naturais e refrigerantes, utilizando a refractometria. A execução de um trabalho deste tipo tem três finalidades. A primeira, relaciona-se com o facto de se poder introduzir e distinguir facilmente, a noção de refracção num meio. Seguidamente, mostrar a utilidade prática de um instrumento simples e passível de se encontrar em qualquer laboratório químico (quer do ensino secundário, quer universitário ou industrial), na resolução de um problema quotidiano. Por último, a execução e posterior tratamento dos dados experimentais, revelará ao realizante, a necessidade de um bom rigor experimental (é necessário o conhecimento rigoroso de, pelo menos, três casas decimais), por forma a que os dados obtidos possam ser validados e utilizados.

\section{Procedimento experimental}

\section{Descrição do procedimento experimental efectuado}

\section{Calibração do refractómetro}

Aprenda a trabalhar com o refractómetro que tem à sua disposição. Calibre-o

\section{Tabela 1- Soluções de sacarose utilizadas na construção da recta de calibração.}

\begin{tabular}{llllll}
\hline Solução & 1 & 2 & 3 & 4 & 5 \\
Sacarose/g & 0 & 10,9 & 16,6 & 21,8 & 27,2 \\
[Sacarose] g/L & 0 & 218 & 320 & 436 & 544 \\
$\mathrm{n}_{20}{ }^{\mathrm{D}}$ & 1,332 & 1,364 & 1,379 & 1,396 & 1,412 \\
\hline
\end{tabular}

A última linha da tabela é meramente indicativa, pois terá de obter os seus próprios valores. com o composto disponibilizado, de preferência bromonaftaleno ou etanol. Pode também utilizar um solvente cujo índice de refracção seja conhecido com rigor, por exemplo, o mais comum num laboratório: água destilada. Verifique o rigor do aparelho de que dispõe, determinando o índice de refracção de outros líquidos, a $20^{\circ} \mathrm{C}$

\section{Rectas de Calibração}

De acordo com as Tabelas 1 e 2, prepare as soluções de sacarose e aspartame, que irá utilizar na construção das rectas de calibração. Pode utilizar o açúcar (sacarose) e adoçante (aspartame) que adquire normalmente numa mercearia ou supermercado. Tenha em conta que, no caso do aspartame, as concentrações a considerar serão, forçosamente, inferiores às escolhidas para a recta de calibração da sacarose (cerca de 10 a 20 vezes),

\section{1.- Sacarose}

Prepare as seguintes soluções (Tabela 1), para um volume total de $50 \mathrm{~mL}$. 0 volume de solução preparada pode ser bastante inferior uma vez que na determinação do índice de refracção apenas se utilizam 2 ou 3 gotas de solução. Os valores aqui apresentados são meramente indicativos (tabela 1).

\section{2- Aspartame (ver tabela 2)}

Repita o procedimento anterior para as soluções da tabela 2 .

Represente graficamente o índice de refracção em função da concentração de sacarose (em g/L). Obterá desta forma a sua recta de calibração da sacarose. 
Tabela 2 - Soluções de aspartame utilizadas na construção da recta de calibração.

\begin{tabular}{llllllllllll}
\hline Solução & 1 & 2 & 3 & 4 & 5 & 6 & 7 & 8 & 9 & 10 & 11 \\
[Ad.]g/L & 0 & 1,032 & 1,970 & 5,026 & 10,960 & 15,010 & 21,582 & 24,958 & 29,930 & 46,120 & 64,600 \\
$\mathrm{n}^{\circ}\left(16^{\circ} \mathrm{C}\right)$ & 1,3333 & 1,3334 & 1,3336 & 1,3340 & 1,3346 & 1,3354 & 1,3365 & 1,3370 & 1,3376 & 1,3400 & 1,3426
\end{tabular}

A última linha da tabela é meramente indicativa, pois terá de obter os seus próprios valores.

Tabela 3 - Índices de refracção medidos por um grupo de alunos para diferentes soluções de sacarose, de acordo com as concentrações da tabela 1.

$\begin{array}{llllll}\text { Soluções } & 1 & 2 & 3 & 4 & 5 \\ \mathrm{n}_{20}{ }^{\mathrm{D}} & 1,3325 & 1,3640 & 1,3810 & 1,3960 & 1,4110\end{array}$

Tabela 4 - Índices de refracção e valores de teor de açúcar obtidos para diferentes refrigerantes, com base na recta de calibração obtida anteriormente.

\begin{tabular}{lll}
\hline Bebidas & $\mathrm{n}_{20^{D}}$ & Teor de açúcar em g/L \\
Coca-Cola $^{\oplus}$ & 1,3485 & 109,7 \\
Pepsi $^{\star}$ & 1,3490 & 113,2 \\
Ice-Tea de Pêssego $^{\bullet}$ & 1,3445 & 82,1 \\
Santal de Pêssego & 1,3550 & 154,5 \\
Compal de Pêssego & 1,3505 & 123,5 \\
Compal de Ananás & 1,3500 & 120,1 \\
Santal de Laranja & 1,3490 & 113,2 \\
Fanta de Laranja & 1,3525 & 137,3
\end{tabular}

Tabela 5- Índices de refracção e determinação da concentração de adoçante* (aspartame) nas bebidas analisadas com base na recta de calibração anterior $\left(n_{D}^{16}=1,3333+1,45 \times 10^{-4} \times[\right.$ Asp. $\left.] \mathrm{g} / \mathrm{L}\right)$.

$\begin{array}{lll}\text { Bebida } & \mathrm{n}_{\mathrm{D}}\left(\mathbf{1 6}^{\circ} \mathbf{C}\right) & \text { [Asp.] g/L } \\ \text { Coca-Cola light }^{\circledast} & 1,3335 & 1,376 \\ \text { Pepsi light } & 1,3335 & 1,376 \\ 7 \text { Up light } & 1,3334 & 0,688 \\ \text { Sumol laranja light }^{\star * *} & 1,3421 & 60,530 \\ \text { Ice-Tea Pêssego light }^{\circledR} & 1,3337 & 2,751\end{array}$

* composição do adoçante: Aspartame e Maltodextrina (sem referência a composição). Considera-se que a maltodextrina está presente em pequena quantidade

** o elevado valor pode reflectir o facto deste sumo possuir resquícios de polpa o que pode conduzir a uma leitura incorrecta do valor do índice de refraccção desta solução.
Pode notar a importância do número de casas decimais considerado, tanto na leitura dos valores experimentais (índices de refracção), como no declive da recta, verificando que o respectivo intervalo de variação é de cerca de 0,01. Uma redução no número de casas decimais da recta de calibração terá consequências no rigor do cálculo do teor de composto.

\section{Determinação do teor de sacarose em bebidas}

Obtenha o índice de refracção de, pelo menos, três bebidas comerciais. Poderá escolher, por exemplo, Fanta ${ }^{\star}, 7 \mathrm{Up}^{\star}$, Sprite $^{\star}$, Coca-Cola ${ }^{\star}$, entre outras. Mais uma vez estas bebidas são meramente indicativas. Não se pretende publicitar qualquer uma delas. Tenha em atenção que pode ter de efectuar diluições das soluções que irá medir no refractómetro.

Determine o teor de açúcar na bebida através da curva de calibração. Note que as bebidas comerciais podem ter outros açúcares dissolvidos, além de outros componentes que podem modificar o índice de refracção da solução, pelo que os resultados obtidos devem ser lidos com alguma reserva.

\section{Determinação do teor de aspartame em bebidas}

Construa a recta de calibração das soluções de aspartame.

Para o caso dos dados constantes da tabela 2, a recta de calibração resultante apresenta-se na Figura 4.

Obtenha o índice de refracção de, pelo menos, três bebidas comerciais. Pode- 